American Journal of Applied Sciences 7 (9): 1210-1214, 2010

ISSN 1546-9239

(C) 2010 Science Publications

\title{
Comparison of Two Regimens of Nigella sativa Extract for Treatment of Subclinical Mastitis Caused by Staphylococcus aureus
}

\author{
${ }^{1}$ Hamideh Ghodrati Azadi and ${ }^{2}$ Nima Farzaneh \\ ${ }^{1}$ Department of Basic Sciences, \\ ${ }^{2}$ Department of Clinical Sciences, \\ Faculty of Veterinary Medicine, \\ Ferdowsi University of Mashhad, Mashhad, Iran
}

\begin{abstract}
Problem statement: Little research has focused on treatment of cows with subclinical mastitis during lactation. The seed of Nigella sativa Linn. (Ranunculaceae), commonly known as black seed or black cumin, is used in folk (herbal) medicine. Approach: Objectives of this study were to evaluate the effect of Nigella sativa Extract (NSE) with two regimens for treatment of subclinical mastitis in lactating dairy cows and to determine which regimen enhanced efficacy of it. Results: From one hundred Holstein dairy research herd in Mashhad-Iran, 83 cows with a total of 157 subclinically Staphylococcus aureus infected quarters were included. Cows were enrolled in the study based on milk somatic cell counts $>200,000 \mathrm{~mL}^{-1}$ and isolation of Staphylococcus aureus in 3 samples obtained 1 week apart. About $10 \mathrm{cc}$ of NSE (in paraffin: $200 \mathrm{mg} \mathrm{cc}^{-1}$ ) was administered via intramammary infusion. First, Cows were divided into three treatment groups. Group 1 (37 cows) received intramammary infusion at each milking ( 3 times daily) for 3 days with 10 cc NSE. Group 2 (24 cows) received the same intramammary infusion but only once daily for 3 days. The third, 22 cows were included as an untreated negative control group. Results in bacteriologic cure of $69.4 \%$ of quarters and $59.5 \%$ of cows (Group 1) compared to $60 \%$ of quarters and $45.8 \%$ of cows (Group 2). Test for mastitis diagnosis Somatic cell counts of milk from quarters that were not cured were higher prior to initiation of treatment than those cured. A bacteriological cure was defined as a treated infected mammary quarter that was bacteriologically negative for the presence of $S$. aureus at 3-7 day after the last treatment. Conclusion: All two Nigella sativa treatment regimens were significantly better than the negative control and the nine dose Nigella sativa treatment regimen treatment group was not significantly better than the three dose treatment group $(\mathrm{p}=0.332)$.
\end{abstract}

Key words: Subclinical mastitis, Staphylococcus aureus, Nigella sativa

\section{INTRODUCTION}

Clinical and subclinical mastitis are the 2 major forms of the diseases. Clinical mastitis results in alterations in milk composition and appearance, decreased milk production, elevated body temperature and swelling, redness, or heat in infected mammary quarters. It is readily apparent and easily detected. However, detection of mammary quarters with subclinical mastitis is more difficult because signs are not readily apparent (Radostits et al., 2000). Consequently, subclinical mastitis, which is the most prevalent form of the disease, often goes undetected. Many subclinical Intramamal Infection (IMI) tend to persist, resulting in elevated milk SCC and decreased milk production, which may lead to development of clinical mastitis and the opportunity for certain mastitis pathogens to spread from infected mammary quarters to uninfected mammary quarters. Acceptance and application of mastitis control programs implemented in the 1960s, including teat disinfection, antibiotic therapy and culling of chronically infected cows, has led to considerable progress in controlling contagious mastitis pathogens. Staphylococcus aureus is one of the most common causes of contagious bovine mastitis and subclinical mastitis in dairy cattle worldwide and 50$100 \%$ of herds may be infected with this pathogen (Radostits et al., 2000; Morgan, 2008)

The seed of Nigella sativa Linn. (Ranunculaceae), commonly known as black seed or black cumin, is used in herbal medicine all over the world for the treatment and prevention of a number of diseases and conditions

Corresponding Author: Hamideh Ghodrati Azadi, Department of Basic Sciences, Faculty of Veterinary Medicine,

Ferdowsi University of Mashhad, Mashhad, Iran Tel/Fax: 00985118763852 
that include asthma, diarrhoea and dyslipidaemia (Hawari and Al-Dabbas, 2008). Nigella (Nigella sativa L.) is an annual herbaceous plant belonging to the Ranunculaceae family growing in countries bordering the Mediterranean Sea and is cultivated throughout India and other tropical regions of the world (Mehta et al., 2008; Saganuwan, 2009; Cheikh-Rouhou et al., 2007). A number of reports have been published on the action of $N$. sativa extracts or its oil on the different bacterial isolated (Al-Haj et al., 2010; Hawari and Al-Dabbas, 2008).

To date, little research has focused on treatment of cows with subclinical mastitis during lactation. Risk factors for bacteriological cure of Staphylococcus aureus infections following antibiotic treatment were reported previously. They included age, number of infected quarters, quarter location and stage of lactation and severity of the inflammation (Sol et al., 2000; Barkema et al., 2006).

An objective of the present study was to evaluate the effect of two regimens of NSE for treatment of naturally occurring subclinical mastitis in lactating dairy cows caused by Staphylococcus aureus. Another objective was to determine which regimen of NSE has enhanced effect for subclinical mastitis.

Recently, reported that the intensity of bacterial shedding was negatively associated with $S$. aureus cure following antibiotic treatment at dry-off. It is worthwhile to determine whether previously identified risk factors for $S$. aureus cure apply to other bacterial species that also often cause subclinical mastitis (Alhaj et al., 2008).

Finally, treatment success should lead to reduction in SCC. Concerning the importance of $S$. aureus mastitis, monitoring of herd for diagnosis of the first cases of infection is necessary for prevention of infection spreading and the culture of milk is considered. We planned to investigate the effects of $N$. sativa seeds on subclinical mastitis by $S$. aureus with paraffin extract of $N$. sativa $10 \mathrm{cc}\left(200 \mathrm{~mL} \mathrm{~mL}^{-1}\right)$ and we treated those infected cows quarters with NSE successful.

\section{MATERIALS AND METHODS}

$N$. sativa seeds were purchased from a local herbal shop with a fair degree of quality assurance in Sabzevar (Khorasan province-Iran) on June 2009. The plant specimen was identified by two botanists in the herbarium department of Iranian Research Institute of Forests and Rangelands, Mashhad, Iran.

Immediately prior to the extraction process, the seeds were ground in a blender to produce a powder then $500 \mathrm{~g}$ of these seeds were added to $2500 \mathrm{~mL}$ liquid parafin for $90 \mathrm{~min}$ and then it was filtered.

The antimicrobial activity of the final Black cumin oil extract was investigated against $S$. aureus bacteria strains in bovine subclinical mastitis.

Lactating dairy cows from a dairy research herd (The University of Mashhad-Iran) were included in this study. All lactating cows with a milk SCC >200,000 $\mathrm{mL}^{-1}$ based on Dairy Herd Improvement herd test data were considered for inclusion. Cows $(n=83)$ were enrolled in the study based on milk SCC >200,000 $\mathrm{mL}^{-1}$ and isolation of $S$. aureus in the 3 samples obtained 1 week apart. Infusion of one syringe of NSE into each affected mammary quarter, which was repeated three times after a $24 \mathrm{~h}$ interval or nine times after an $8 \mathrm{~h}$ interval for 3 days. In that herd, the principal investigator monitored cows for subclinical mastitis using routine cow SCC results. A cow was considered to have subclinical mastitis (and thus potentially qualify for enrollment) if the SCC was greater than 200,000 cells $\mathrm{mL}^{-1}$ twice in the test The cows were all in mid (156 days) lactation, weighed $595 \pm 25 \mathrm{~kg}$ and were milked three times daily throughout the study. The cows had been lactating for $5 \pm 9$ months and were milked 3 times daily throughout the study. The average daily milk production was $30 \mathrm{~kg}$ at the start of the experiment. We confirmed that the mastitis was $S$. aureus-induced by performing weekly subclinical cultures, SCC and cultures of total bacteria and $S$. aureus prior to the experiment.

Feed intake was unchanged throughout the experiments in both groups. The daily milk production in none of groups improved after treatment and no significant difference was observed between the treatment groups and the control, indicating that the treatment has no effect on enhancing the milk yield. The cows did not have clinical mastitis, but at least 1 quarter was subclinically and spontaneously infected with S. aureus and had elevated milk SCC (above 200 000 cells $\mathrm{mL}^{-1}$ ) and the average of the number of affected quarters per cow was 2 quarters. The counts were significantly lowered $(p<0.01)$ by the NSE, meaning the NSE effect on SCC between days 0 and 3 and also days 3 and 7. And the counts were greater ( $>0.01)$ by the paraffin, meaning paraffin has no effect on SCC between days 0 and 3 and also days 3 and 7 .

Infected mammary quarters of cows in the nine dose -NSE treatment regimen (group1) $(n=37$ infected cows, $72 \mathrm{IMI}$ ) were treated three times daily with $10 \mathrm{cc}$ of NSE per quarter for 3 consecutive days.

Infected mammary quarters of cows in the three dose NSE treatment regimen (Group 2) $(n=24$ infected cows, 35 IMI) were treated once daily $10 \mathrm{cc}$ of NSE per 
quarter for 3 consecutive days. Twenty two cows with 50 IMI were included as an untreated negative control group. Infected mammary quarter (s) of each cow included in the study, except for cows in the untreated negative control group, were infused intramammarily with NSE via full insertion of the plastet cannula into the teat end. Somatic cell count was measured on each quarter. Mammary quarter foremilk samples were obtained 0 and 3 day before treatment, immediately prior to treatment and 3-7 day after the last treatment for microbiological evaluation. All samples were collected immediately before regular milking using standard procedures described by the National Mastitis Council (Abdulelah and Zainal-Abidin, 2007).

Before sample collection, teats were dipped in a premilking teat disinfectant, cleaned thoroughly, dried with paper towels and teat ends were sanitized with swabs containing 70\% isopropyl alcohol.

Milk samples were examined following procedures recommended by the National Mastitis Council and as described by with modifications (Abdulelah and ZainalAbidin, 2007) briefly, foremilk samples (10 $\mu \mathrm{L})$ from each quarter were plated onto one quadrant of a trypticase soy agar plate supplemented with $5 \%$ defibrinated sheep blood. Plates were incubated at $37^{\circ} \mathrm{C}$ and bacterial growth was observed and recorded at $24 \mathrm{~h}$ intervals for 3 day. Bacteria on primary culture medium were identified tentatively according to colony morphologic features, hemolytic characteristics and catalase test. Isolates identified presumptively as staphylococci were tested for coagulase by the tube coagulase method.

The milk SCC was determined by the Dairy Herd Improvement Association Laboratory (Mashhad). Milk samples $(-25 \mathrm{~mL})$ for SCC determination were collected before cows were milked and after conducting the strip cup evaluation and collection of milk for microbiological evaluation.

A bacteriological cure was defined as an infection that was negative for the presence of previously identified $S$. aureus at 3 and 7 day after last treatment. The percentage of subclinical IMI cured in quarters receiving two regimens (three-dose and nine-dose of NSE) was compared with the percentage cured in the untreated control and percentage of subclinical IMI cured by the nine-dose regimen was also compared with the percentage of subclinical IMI cured in the threedose regimen group.

Data were analyzed by multidimensional contingency table methodology, which compared cure rates between treatments by use of Pearson $\times 2$ (by the MINITAB 15 software).

In this case, treatment by response information could be pooled over herd and the Pearson $\times 2$ statistic for 2 way tables was the appropriate statistic to compare treatments. To determine normality of each group, we used the one sample Kolomogorov-Smirnov Test. It was used to compare milk bacterial growth scores between the two groups for each sampling occasion and the scores between pre-treatment and after treatment in each group. The pre-treatment values for each cow or udder quarter were calculated. Then, this pre-treatment value and each post-treatment value within each cow or udder quarter were compared by paired t-test. Thereafter, for each parameter, the Change between the pre-treatment value and the value on each post-treatment sampling were calculated.

Daily milk production in none of groups were improved after treatment and no significant difference was observed between treatment group and control indicating that treatment has no effect on enhancing milk yield.

The number of quarters enrolled in the study (n) is presented. If one cure rate is shown, this presents the average cure rate without consideration of host factors and the number of quarters cured out of number treated is shown.

\section{RESULTS}

There were 157 subclinical IMI in the 83 cows enrolled in this study which were due to $S$. aureus.

The first analysis, the effect of NSE against all these subclinical IMI was 60 and $69.4 \%$ for the threedose and nine-dose of NSE treatment regimens, respectively. All two NSE treatment regimens were significantly better than the negative control and the nine dose NSE treatment regimen treatment group wasn't better than the three dose treatment group $(\mathrm{p}>0.05)$.

All NSE treatment regimens were significantly better than the negative control and both the three dose and nine dose NSE therapy treatment regimens had significantly higher bacterial cure rates than the control treatment regimen.

There were 72 quarters from 37 cows (study 1) and 35 quarters in 24 cows (study 2 ) correctly enrolled for sub clinical mastitis occurred with isolated $S$. aureus. Quarters with clinical mastitis during the observation period or with incomplete data were excluded from statistical analysis. The distribution of parity, stage of lactation, number of enrolled quarters per cow, proportion of front $\mathrm{Vs}$ rear quarters and pretreatment SCC level showed no major differences among treatment groups within study. Bacteriological cure results by treatment group are in Table 1. 
Am. J. Applied Sci., 7 (9): 1210-1214, 2010

Table 1: Pairwise comparison of subclinical mastitis cure rates following two regimens of NSE

\begin{tabular}{|c|c|c|c|c|}
\hline \multirow[b]{2}{*}{ NSE treatment regimen } & \multicolumn{4}{|c|}{ Two sided p-values/ Pearson Chi-Square ${ }^{1}$} \\
\hline & Cured $(\%)^{2}$ & 3 dose & 9 dose & Control \\
\hline 3 dose & $21 / 35(60 \%)$ & $\ldots$ & $0.33 / 0.94$ & $0.00 / 29.628$ \\
\hline 9 dose & $50 / 72(69.4 \%)$ & & $\ldots$ & $0.00 / 48.34$ \\
\hline Negative control & $3 / 50(6 \%)$ & & & $\ldots$ \\
\hline
\end{tabular}

In the untreated group, the CURE percentage decreased as lactation progressed. As expected, percentage CURE was also significantly lower with increased parity and higher number of colonies.

The geometric mean SCC did not differ between d 3 and 7 posttreatment and were averaged for all analyses. LnSCCpost was significantly lower than $\operatorname{lnSCCpre}$ in all treatment groups.

\section{DISCUSSION}

According to the results of this research and the previous studies on bovine mastitis in Iran (Abu-AlBasal, 2009; Eslampour et al., 2009), S. aureus mastitis has a high prevalence in dairy cattle and remains as a main problem in herds. There were no signs of toxicity in either clinical trial. A significant difference in the cure rate occurred between the negative control and the experimental groups at $\mathrm{p}=0.05$.

The purpose of this study was an attempt to treatment $S$. aureus intramammary natural infections subclinical by NSE in condition of Iran and to compare the results with two groups of treatment. The used 3 times in $24 \mathrm{~h}$ method was the same to treat $S$. aureus strains isolated from intramammary infections as 1 time in $24 \mathrm{~h}$ and comparative cure rates reflected that both regimens of NSE therapy had the same treatment efficacy.

Results of our work and others showed Nigella sativa therapy against all subclinical $S$. aureus IMI was USFUL. Following treatment of mastitis during lactation (Alhaj et al., 2008) reported a statistically significant reduction of the $S$. aureus concentration present in milk. This was accompanied by a transient decrease in SCC that had returned to near pretreatment levels by $\mathrm{d} 7$ post-treatment. In contrast, in the present study there was no evidence of a post-treatment return to high pretreatment SCC levels for cured quarters and present results suggest NSE for lactation therapy of subclinical mastitis.

Post treatment SCC was associated with treatment regimen and with other factors, i.e., pre treatment SCC, quarter location and the interaction of parity with quarter location and pre treatment SCC. These other factors did not vary significantly with treatment regimen. This confirms the study of (Bradley and Green, 2009).

In addition, quarter location, InSCCpre and the interaction of parity with $\operatorname{lnSCCpre}$ and quarter location were significantly associated with $\operatorname{lnSCCpost}$ (El Bagir et al., 2010; Mungube et al., 2005).

Regardless of treatment regimen, bacteriological cure rate was higher in younger animals and when fewer colonies had been isolated pre-treatment (not shown). Stage of lactation also affected bacteriological cure, but its effect varied with the treatment regimen.

\section{CONCLUSION}

As the number of quarters infected per cow increased, there was a decrease in the cow cure rates. Results of our work (Not published) support the concept that black seed oil possesses significant antimicrobial activity against $S$. aureus and nine-dose NSE is as effective at eliminating IMIas three- dose NSE. According to these advantages of NSE we recommended to use it as antibacterial for bovine mastitis. Further work is needed on the formulation of this herb.

\section{ACKNOWLEDGMENT}

This study was supported by research fund of Ferdowsi university of Mashhad, Iran (project No: 12490, 83/3/20).

\section{REFERENCES}

Abdulelah, H.A.A. and B.A.H. Zainal-Abidin, 2007. In vivo anti-malarial tests of Nigella sativa (black seed) different extracts. Am. J. Pharm. Toxicol., 2: 46-50.

http://www.scipub.org/fulltext/AJPT/AJPT224650.pdf

Abu-Al-Basal, M.A., 2009. In vitro and In vivo antimicrobial effects of Nigella sativa Linn. seed extracts against clinical isolates from skin wound infections. Am. J. Applied Sci., 6: 1440-1447. http://www.scipub.org/fulltext/ajas/ajas6814401447.pdf 
Alhaj, N.A., M.N. Shamsudin, H.F. Zamri and R. Abdullah, 2008. Extraction of essential oil from Nigella sativa using supercritical carbon dioxide: study of antibacterial activity. Am. J. Pharm. Toxicol., 3: 225-228.

http://www.scipub.org/fulltext/AJPT/AJPT34225228.pdf

Al-Haj, N.A., N.I. Mashan, M.N. Shamsudin, H. Mohamad and C.S. Vairappan et al., 2010. Antibacterial activity of marine source extracts against multidrug resistance organisms. Am. J. Pharm. Toxicol., 5: 95-102.

http://www.scipub.org/fulltext/AJPT/AJPT5295102.pdf

Barkema, H.W., Y.H. Schukken and R.N. Zadoks, 2006. The role of cow, pathogen and treatment regimen in the therapeutic success of bovine staphylococcus aureus mastitis. J. Dairy Sci., 89: 1877-1895. DOI: 10.3168/JDS.S0022-0302 (06)72256-1

Bradley, A.J. and M.J. Green, 2009. Factors affecting cure when treating bovine clinical mastitis with cephalosporin-based intramammary preparations. J. Dairy Sci., 92: 1941-1953. DOI: 10.3168/jds.20081497

Cheikh-Rouhou, S., S. Besbes, B. Hentati, C. Blecker and C. Deroanne et al., 2007. Nigella sativa L.: Chemical composition and physicochemical characteristics of lipid fraction. Food Chem., 101: 673-681. DOI: 10.1016/J.FOODCHEM.2006.02.022

El Bagir, N.M., I.T.O. Farah, S.M.B. Elhag, A. Alhaidary and H.E. Mohamed et al., 2010. Immune response and pasteurella resistance in rabbits fed diets containing various amounts of black cumin seeds. Am. J. Anim. Vet. Sci., 5: 163-167. http://www.scipub.org/fulltext/AJAV/AJAV52163167.pdf

Eslampour, M.A., P. Hovareshti, M. Feizabadi, M. Aligholi and M. Bolourchi et al., 2009. Molecular characterization of Staphylococcus aureus isolated from bovine mastitis in Iran. Vet. Microbiol., 139: 207-208. DOI: 10.1016/J.VETMIC.2009.05.001
Hawari, A.D. and F. Al-Dabbas, 2008. Prevalence and distribution of mastitis pathogens and their resistance against antimicrobial agents in dairy cows in Jordan. Am. J. Anim. Vet. Sci., 3: 36-39. http://www.scipub.org/fulltext/AJAV/AJAV313639.pdf

Mehta, B.K., M. Verma and M. Gupta, 2008. Novel lipid constituents identified in seeds of Nigella sativa (Linn). J. Braz. Chem. Soc., 19: 458-462. http://www.scielo.br/pdf/jbchs/v19n3/a12v19n3.pdf

Morgan, M., 2008. Methicillin-resistant Staphylococcus aureus and animals: Zoonosis or humanosis? J. Antimicrob. Chemother., 62: 1181-1187. PMID: 18819971

Mungube, E.O., B.A. Tenhagen, F. Regassa, M.N. Kyule and Y. Shiferaw et al., 2005. Reduced milk production in udder quarters with subclinical mastitis and associated economic losses in crossbred dairy cows in Ethiopia, Trop. Anim. Health Prod., 37: 503-512. DOI: 10.1007/s11250005-7049-y

Radostits, O.M., C.C. Gay, D.C. Blood, K.W. Hinchcliff and C. Gay et al., 2000. Veterinary Medicine: A Textbook of the Diseases of Cattle, Sheep, Pigs, Goats and Horses. 9th Edn., Saunders Ltd., London, UK., ISBN: 10: 0702026042, pp: 1877.

Saganuwan, A.S., 2009. Tropical plants with antihypertensive, antiasthmatic and antidiabeti value. J. Herbs Spices Med. Plants, 15: 24-44. DOI: $10.1080 / 10496470902787477$

Sol, J., O.C. Sampimon, H.W. Barkema and Y.H. Schukken, 2000. Factors associated with cure after therapy of clinical mastitis caused by staphylococcus aureus. J. Dairy Sci., 83: 278-284. PMID: 10714861 